Review

\title{
Guidelines for Tracheostomy From the Korean Bronchoesophagological Society
}

\author{
Korean Bronchoesophagological Society Guideline Task Force; Inn-Chul Nam ${ }^{1}$ (i) · Yoo Seob Shin ${ }^{2}$ (i) $\cdot$ Woo-Jin Jeong ${ }^{3}$ (i)

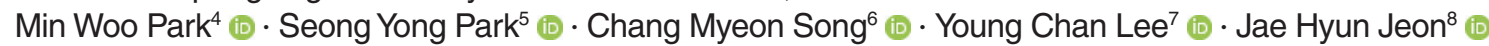

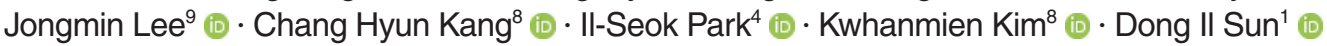 \\ ${ }^{1}$ Department of Otolaryngology-Head and Neck Surgery, College of Medicine, The Catholic University of Korea, Seoul; ${ }^{2}$ Department of \\ Otolaryngology-Head and Neck Surgery, Ajou University School of Medicine, Suwon; ${ }^{3}$ Department of Otorhinolaryngology-Head and Neck \\ Surgery, Seoul National University Bundang Hospital, Seoul National University College of Medicine, Seongnam; ${ }^{4}$ Department of \\ Otorhinolaryngology-Head and Neck Surgery, Hallym University College of Medicine, Seoul; ${ }^{5}$ Department of Thoracic and Cardiovascular \\ Surgery, Yonsei University College of Medicine, Seoul; ${ }^{6}$ Department of Otolaryngology-Head and Neck Surgery, Hanyang University College of \\ Medicine, Seoul; ${ }^{7}$ Department of Otolaryngology-Head and Neck Surgery, Kyung Hee University School of Medicine, Seoul; ${ }^{8}$ Department of \\ Thoracic and Cardiovascular Surgery, Seoul National University College of Medicine, Seoul; ${ }^{9}$ Division of Pulmonary, Allergy and Critical Care \\ Medicine, Department of Internal Medicine, College of Medicine, The Catholic University of Korea, Seoul, Korea
}

The Korean Bronchoesophagological Society appointed a task force to develop a clinical practice guideline for tracheostomy. The task force conducted a systematic search of the Embase, Medline, Cochrane Library, and KoreaMed databases to identify relevant articles, using search terms selected according to key questions. Evidence-based recommendations for practice were ranked according to the American College of Physicians grading system. An external expert review and a Delphi questionnaire were conducted to reach a consensus regarding the recommendations. Accordingly, the committee developed 18 evidence-based recommendations, which are grouped into seven categories. These recommendations are intended to assist clinicians in performing tracheostomy and in the management of tracheostomized patients.

Keywords: Tracheotomy; Tracheostomy; Clinical Guideline

\section{INTRODUCTION}

Tracheostomy is one of the oldest and most commonly performed surgical procedures in critically ill patients [1]. It is used

\footnotetext{
- Received March 16, 2020

Revised April 29, 2020

Accepted May 19, 2020

- Corresponding author: Dong II Sun

Department of Otolaryngology-Head and Neck Surgery, Seoul St. Mary's

Hospital, College of Medicine, The Catholic University of Korea,

222 Banpo-daero, Seocho-gu, Seoul 06591, Korea

Tel: +82-2-2258-6212, Fax: +82-2-595-1354

E-mail: hnsdi@catholic.ac.kr

- Co-Corresponding author: Kwhanmien Kim

Department of Thoracic and Cardiovascular Surgery, Seoul National

University Bundang Hospital, Seoul National University College of

Medicine, 82 Gumi-ro 173beon-gil, Bundang-gu, Seongnam 13620, Korea

Tel: +82-31-787-7131, Fax: +82-31-787-4050

E-mail: kmkim0070@snubh.org
}

to manage upper airway obstruction, prolonged endotracheal intubation, and bronchial hygiene [2]. However, the indications for tracheostomy, the optimal surgical technique, and the proper management of tracheostomy patients remain controversial. Nonetheless, with the increasingly widespread use of mechanical ventilation, these clinical challenges must be addressed [3]. For example, despite its wide use, there are currently no comprehensive evidence-based clinical guidelines for tracheostomy. In addition, novel techniques, such as percutaneous dilatational tracheostomy (PDT), have been developed, and several such techniques have been widely implemented.

The guidelines described herein are based on the available scientific evidence and consensus of a group of experts at the Korean Bronchoesophagological Society, which is composed of head and neck surgeons, thoracic surgeons, pulmonologists, and anesthesiologists. It should be noted that the correct terminology, "tracheotomy" or "tracheostomy," is also a matter of debate,

Copyright $\odot 2020$ by Korean Society of Otorhinolaryngology-Head and Neck Surgery

This is an open-access article distributed under the terms of the Creative Commons Attribution Non-Commercial License (https://creativecommons.org/licenses/by-nc/4.0)

which permits unrestricted non-commercial use, distribution, and reproduction in any medium, provided the original work is properly cited. 
although in published reports the two terms are used interchangeably. Both are derived from the Greek language: tracheotomy simply refers to a surgical "opening of the trachea," whereas tracheostomy also refers to a stoma and thus, strictly speaking, implies a permanent opening made in the neck by suturing skin flaps onto the tracheal walls [4]. For the purpose of guideline development, the terminology was discussed by the task force of the Korean Bronchoesophagological Society during the first conference call and a unanimous decision was made to use the term "tracheostomy."

\section{Target population and intended users}

These guidelines were developed for clinicians performing tracheostomy and managing tracheostomized patients, regardless of clinical department. The recommendations address general aspects of tracheostomy in various situations (elective and emergent) and in specific patient groups (pediatric and adult), the use of various techniques (mediastinal tracheostomy and PDT), and postoperative management.

\section{MATERIALS AND METHODS}

\section{Organization of the committee}

The chairman of the task force (ISP) responsible for the development of tracheostomy guidelines was recommended by the Korean Bronchoesophagological Society. The committee also included a secretary (ICN) and eight members (YSS, WJJ, MWP, SYP, CMS, YCL, JHJ, and JML). The first meeting was held in May 2018, and a total of 18 meetings were held. The task force had complete editorial independence from the Korean Bronchoesophagological Society.

\section{Selection of key questions}

The goal of the task force was the development of comprehensive tracheostomy guidelines. Accordingly, seven categories were established: elective tracheostomy, emergency tracheostomy, pediatric tracheostomy, mediastinal tracheostomy, decannulation, management, and PDT. Key questions to be addressed for each category were formulated (Table 1).

\section{H I G H L I G H T S}

- The Korean Bronchoesophagological Society developed a practice guideline for tracheostomy.

- This guideline was developed for any physician performing tracheostomy, regardless of his or her specialty, and covers tracheostomy-related general topics.

- These recommendations are intended to assist clinicians in performing tracheostomy and in the management of tracheostomized patients.

\section{Literature search and quality assessment}

During the third committee meeting, held on August 13, 2018, the committee reached a consensus regarding the keywords to be used in the literature search for information enabling a systematic review of the key questions. A search of the Embase, Medline, Cochrane Library, and KoreaMed databases for all relevant papers was performed on November 8, 2018 using these keywords. The search results were saved in Endnote X6 (Thomson Reuters, New York, NY, USA) and duplicates were removed. The inclusion criteria were as follows: (1) a human study population; (2) article, review, or article in press; and (3) English-language or Korean-language text. Following a title review and the exclusion of irrelevant articles, the remaining selected articles were reviewed independently by two committee members who determined whether each article should be excluded or included. Case reports, commentaries, and older publications for which the full text was not available were excluded. The keywords used for the selected key questions, number of retrieved papers, and search results are listed in Supplementary Table 1.

Literature quality, grades of recommendations, and strength of evidence

The abstracts and text of the papers selected using the above-described methods were reviewed. The quality of the studies was classified as follows: (1) randomized controlled trials (RCTs) or well-designed systematic reviews or meta-analyses, (2) non-RCTs; (3) high-quality case-control or cohort studies, including multicenter studies; (4) case reports or clinical studies without control groups; and (5) expert opinions. As high-quality papers (e.g., those describing well-designed RCTs) in the field of surgical management are extremely rare, well-designed meta-analyses and systematic reviews were classified as high-quality evidence. The risk of bias assessment tool for nonrandomized studies (RoBANS) tool [5] was used in the quality assessment of non-RCTs and observational studies, and A MeasurementTool to Assess the Methodological Quality of Systematic Reviews (AMSTAR) [6] was used in the assessment of systematic reviews and meta-analyses.

The American College of Physicians (ACP) grading system was adopted by the task force [7]. Because this system uses only two basic levels of recommendation, strong or weak, it has the advantages of simplicity and ease of interpretation by both clinicians and patients [8]. The level of evidence was classified as high-quality, moderate-quality, or low-quality (Table 2). For controversial issues with inconsistent data, a decision of "no recommendation" was made because of insufficient evidence. This assessment did not imply that the committee issued a negative ruling, but only that a for-or-against opinion could not be formulated. The interpretation of the grading system followed the guidelines provided by the ACP and is summarized in Table 3. The level of evidence was reviewed, and on the basis of the references used to make each recommendation, a consensus was reached during the 15 th committee meeting. 
Table 1. Key questions addressed in this guideline

Key question
KQ 1. What are the indications for tracheostomy?
KQ 2. When is the appropriate timing for tracheostomy following intubation?
KQ 3. What is the proper setting for elective tracheostomy?
KQ 4. What is the preferred direction of the skin incision?
KQ 5. How should the thyroid isthmus be managed?
KQ 6. What is the preferred method of tracheal incision?
KQ 7. What are the indications for emergency tracheostomy?
KQ 8. How is emergency tracheostomy performed?
KQ 9. What are the technical differences between pediatric and adult tracheostomy?
KQ 10. What are the selection criteria in choosing an appropriate cannula in pediatric patients?
KQ 11. What are the indications for mediastinal tracheostomy?
KQ 12. What types of additional procedures are needed for mediastinal tracheostomy?
KQ 13. What are the indications for decannulation of a tracheostomy tube?
KQ 14. How is decannulation performed?
KQ 15. When should the tracheostomy tube first be changed?
KQ 16. What is the appropriate postoperative care after tracheostomy?
KQ 17. When should PDT be performed for patients in the ICU?
KQ 18. Which is the appropriate procedure for patients who need tracheostomy, PDT or surgical tracheostomy?

PDT, percutaneous dilatational tracheostomy; ICU, intensive care unit.

Table 2. Levels of evidence

\begin{tabular}{ll}
\hline Term & \multicolumn{1}{c}{ Definition } \\
\hline High-quality evidence & RCT without important limitations or overwhelming evidence from observational studies \\
Moderate-quality evidence & RCT with important limitations or strong evidence from observational studies \\
Low-quality evidence & Observational studies/case studies \\
\hline
\end{tabular}

$\mathrm{RCT}$, randomized controlled trial.

Table 3. Interpretation of American College of Physicians grading system

\begin{tabular}{|c|c|c|c|}
\hline Grade of recommendation & Benefit versus risks and burdens & Interpretation & Implication \\
\hline \multicolumn{4}{|l|}{ Strong recommendation } \\
\hline $\begin{array}{l}\text { High quality of evidence } \\
\text { Moderate quality of evidence } \\
\text { Low quality of evidence }\end{array}$ & $\begin{array}{l}\text { Benefits clearly outweigh risks } \\
\text { and burden or vice versa. }\end{array}$ & $\begin{array}{l}\text { Strong recommendation, can apply } \\
\text { to most patients in most } \\
\text { circumstances without reservation. } \\
\text { Strong recommendation, but may } \\
\text { change when higher-quality } \\
\text { evidence becomes available. }\end{array}$ & $\begin{array}{l}\text { For patients: most would want the } \\
\text { recommended course and only a small } \\
\text { proportion would not. } \\
\text { For clinicians: most patients should receive } \\
\text { the recommended course of action. }\end{array}$ \\
\hline \multicolumn{4}{|l|}{ Weak recommendation } \\
\hline $\begin{array}{l}\text { High quality of evidence } \\
\text { Moderate quality of evidence } \\
\text { Low quality of evidence }\end{array}$ & $\begin{array}{l}\text { Benefits closely balanced with } \\
\text { risk and burden } \\
\text { Uncertainty in the estimates of } \\
\text { benefits, risks, and burden; } \\
\text { benefits, risks, and burden may } \\
\text { be closely balanced. }\end{array}$ & $\begin{array}{l}\text { Weak recommendation, best action } \\
\text { may differ depending on } \\
\text { circumstances or patients' or } \\
\text { societal values. } \\
\text { Very weak recommendation, other } \\
\text { alternatives may be reasonable. }\end{array}$ & $\begin{array}{l}\text { For patients: most would want the } \\
\text { recommended course of action but some } \\
\text { would not. A decision may depend on an } \\
\text { individual's circumstances. } \\
\text { For clinicians: different choices will be } \\
\text { appropriate for different patients, and a } \\
\text { management decision consistent with a } \\
\text { patient's values, preferences, and } \\
\text { circumstances should be reached. }\end{array}$ \\
\hline \multicolumn{4}{|l|}{ No recommendation } \\
\hline Insufficient evidence & $\begin{array}{l}\text { Balance of benefits and risks } \\
\text { cannot be determined. }\end{array}$ & $\begin{array}{l}\text { Insufficient evidence to recommend } \\
\text { for or against routinely providing } \\
\text { the service }\end{array}$ & $\begin{array}{l}\text { For patients: decisions based on evidence } \\
\text { from scientific studies can not be made. } \\
\text { For clinicians: decisions based on evidence } \\
\text { from scientific studies can not be made. }\end{array}$ \\
\hline
\end{tabular}




\section{Consensus regarding recommendations and manuscript development}

The recommendations were sent via e-mail to senior members of the Korean Bronchoesophagological Society to elicit expert opinions. Based on the comments of the six responding members, the guidelines were revised and finalized. A Delphi panel was established, composed of experts with $>10$ years of experience in the Korean Bronchoesophagological Society. This format ensured that the panel was representative of the group of experts. The panel comprised 27 members to whom a Delphi questionnaire and a draft of the guidelines were sent via e-mail. The level of agreement was graded using the following Likert scale: (1) fully agree, (2) agree, (3) neither agree nor disagree, (4) disagree, and (5) totally disagree. If more than two-thirds of the panel members responded with (1) or (2), the recommendation was ultimately accepted. After the first round of surveys using the Delphi questionnaire, 24 members replied, corresponding to a response rate of $88.9 \%$. A consensus was achieved for all recommendations (Supplementary Table 2).

\section{GUIDELINES FORTRACHEOSTOMY}

Tracheostomy is performed in many clinical departments, including departments of otolaryngology, chest surgery, general surgery, pulmonology, and intensive care medicine. The following guideline was developed for any physician performing tracheostomy, regardless of his or her specialty, and covers tracheostomy-related general topics (Table 4).

\section{A. Elective tracheostomy}

\section{A1. What are the indications for tracheostomy?}

\section{Recommendation 1}

(A) The airway of patients with upper airway obstruction (infection, tumorous condition, trauma) should be secured via tracheostomy (strong recommendation, lowquality evidence).

(B) Tracheostomy is recommended in patients requiring prolonged intubation (weak recommendation, low-quality evidence).

(C) Tracheostomy is recommended for more efficient pulmonary hygiene (weak recommendation, low-quality evidence).

(D) Tracheostomy is recommended to facilitate ventilation support/ventilator weaning (weak recommendation, lowquality evidence).

(E) Tracheostomy is recommended for airway protection in patients with neurologic diseases (weak recommendation, low-quality evidence).

Table 4. Organization of the guidelines of tracheostomy

\begin{tabular}{|c|c|c|}
\hline Location key & Section & Item \\
\hline A & Elective tracheostomy & \\
\hline A1 & What are the indications for tracheostomy? & $\mathrm{R} 1$ \\
\hline $\mathrm{A} 2$ & When is the appropriate timing for tracheostomy following intubation? & $\mathrm{R} 2$ \\
\hline A3 & What is the proper setting for elective tracheostomy? & $\mathrm{R} 3$ \\
\hline A4 & What is the preferred direction of the skin incision? & $\mathrm{R} 4$ \\
\hline A5 & How should the thyroid isthmus be managed? & R5 \\
\hline A6 & What is the preferred method of tracheal incision? & R6 \\
\hline $\mathrm{B}$ & Emergency tracheostomy & \\
\hline B1 & What are the indications for emergency tracheostomy? & $\mathrm{R} 7$ \\
\hline B2 & How is emergency tracheostomy performed? & $\mathrm{R} 8$ \\
\hline C & Pediatric tracheostomy & \\
\hline $\mathrm{C} 1$ & What are the technical differences between pediatric and adult tracheostomy? & $\mathrm{R} 9$ \\
\hline $\mathrm{C} 2$ & What are the selection criteria in choosing an appropriate cannula in pediatric patients? & $\mathrm{R} 10$ \\
\hline $\mathrm{D}$ & Mediastinal tracheostomy & \\
\hline D1 & What are the indications for mediastinal tracheostomy? & $\mathrm{R} 11$ \\
\hline D2 & What types of additional procedures are needed for mediastinal tracheostomy? & $\mathrm{R} 12$ \\
\hline $\mathrm{E}$ & Decannulation of the tube & \\
\hline E1 & What are the indications for decannulation of a tracheostomy tube? & $\mathrm{R} 13$ \\
\hline E2 & How is decannulation performed? & $\mathrm{R} 14$ \\
\hline $\mathrm{F}$ & Postoperative management & \\
\hline $\mathrm{F} 1$ & When should the tracheostomy tube first be changed? & $\mathrm{R} 15$ \\
\hline F2 & What is the appropriate postoperative care after tracheostomy? & $\mathrm{R} 16$ \\
\hline G & Percutaneous dilatational tracheostomy & \\
\hline G1 & When should PDT be performed for patients in the ICU? & $\mathrm{R} 17$ \\
\hline G2 & Which is the appropriate procedure for patients who need tracheostomy, PDT or surgical tracheostomy? & $\mathrm{R} 18$ \\
\hline
\end{tabular}

PDT, percutaneous dilatational tracheostomy; ICU, intensive care unit. 
Tracheostomy is one of the most frequent surgical procedures performed in hospitals. Its goals include the relief of upper airway obstruction, as well as the facilitation of ventilator support and weaning in patients requiring prolonged intubation. Despite the lack of studies comparing tracheostomy/cricothyroidotomy with manual ventilation/intubation for the emergent relief of airway obstruction, a direct approach to the trachea remains a strongly recommended procedure $[9,10]$.

Among patients who require ventilator support, $>25 \%$ eventually undergo tracheostomy [11]. However, whether tracheostomy is more successful than prolonged intubation in reducing laryngotracheal complications is unclear. Stauffer et al. [12] reported a higher rate of procedure-related complications and tracheal stenosis in the tracheostomy group than in patients treated using prolonged intubation. The benefits of tracheostomy versus prolonged intubation regarding the incidence of pneumonia, the duration of mechanical ventilation, and overall mortality have been investigated in many studies, but the results are controversial.

Several recent studies determined that there was a lower probability of pneumonia in patients who received early tracheostomy than in those who received late tracheostomy [13-17], but the opposite result has also been reported [18-20]. Inconsistent findings have also been obtained with respect to the advantage of early tracheostomy in preventing pneumonia, with insufficient support for a definite necessity of early tracheostomy. The highly heterogeneous nature of these investigations partially explains the difficulty in reaching a consensus.

A recent meta-analysis showed that there was a significant reduction in the duration of mechanical ventilation in patients who underwent early rather than late tracheostomy [21]. Another review reported that there were significantly fewer intensive care unit (ICU)-related complications, a shorter length of ICU stay, and lower overall mortality in patients who received early tracheostomy [22]. The meta-analysis was based on 32 studies comprising 219,727 patients. With an odds ratio of 0.8 (95\% confidence interval, $0.7-0.9 ; P<0.01$ ), early tracheostomy is favored over late tracheostomy for reducing mortality in adults, but there was no significant difference in long-term mortality [22].

\section{A2. When is the appropriate timing for tracheostomy following intubation?}

\section{Recommendation 2}

(A) Clinicians should consider tracheostomy in patients with an ongoing need for mechanical ventilation at least 7-14 days after intubation (weak recommendation, low-quality evidence).

(B) Early tracheostomy can be recommended even in critically ill patients (weak recommendation, low-quality evidence).
The ideal timing of tracheostomy in patients requiring prolonged intubation has yet to be determined, despite the importance of this information. Tracheostomy can provide more secure and comfortable airway control, decrease both airway dead space and airway resistance, improve the clearance of pulmonary secretions, and reduce sedative usage, the duration of mechanical ventilation, and the length of ICU/hospital stay, thereby lowering overall mortality [15,23-31]. According to a recent meta-analysis of adult patients who needed prolonged endotracheal intubation, early tracheostomy significantly reduced hospitalacquired pneumonia, the duration of mechanical ventilation, the length of ICU stay, and mortality, especially when tracheostomy was performed within the first 7 days of intubation $[21,22]$.

However, investigations into the clinical outcome of tracheostomy must be interpreted with caution, given the high heterogeneity with respect to inclusion and exclusion criteria, clinical characteristics, surgical techniques, and definition of timing. In addition, not all of the RCTs compared the outcomes of early versus late tracheostomy. Lastly, because it is impossible to accurately predict whether a patient will require mechanical ventilation, decision-making continues to be based on the clinical judgement of the primary physician, which may result in selection bias.

\section{A3. What is the proper setting for elective tracheostomy?}

\section{Recommendation 3}

Elective tracheostomy can be performed either in the operating room or in the ICU (weak recommendation, low-quality evidence).

Tracheostomy is widely performed in hospitalized, critically ill patients. However, the proper setting for elective tracheostomy is controversial. At most institutions, tracheostomy is preferentially performed at the bedside, rather than in the operating room, due to the lower costs, shorter operating time, and avoidance of the risks related to transferring critically ill patients to the operating room [32-34]. A meta-analysis of 21 investigations revealed that there was a perioperative complication rate of 3\% [35], and a recent retrospective review reported an overall perioperative complication rate of $8 \%$ among 97 patients who underwent tracheostomy in the ICU [34]. Both rates are generally acceptable, although they were determined in nonrandomized trials. There have been few investigations comparing the outcomes of tracheostomy performed at the bedside versus in the operating room. Tracheostomy may be performed when appropriate at the bedside without an increased risk of complications, but the results and safety of the procedure remain uncertain. 


\section{A4. What is the preferred direction of the skin incision?}

\section{Recommendation 4}

A horizontal skin incision is recommended to prevent an unsightly scar in patients undergoing elective tracheostomy (weak recommendation, low-quality evidence).

No well-designed comparative studies have investigated which type of skin incision is optimal. Horizontal and vertical skin incisions are typically performed, whereas X-shaped skin incisions are an option in pediatric patients. Most reports of skin incisions are limited to experts' preferences or opinions. One study compared post-tracheostomy tracheal stenosis according to whether a vertical or horizontal skin incision had been made, but the differences were not significant [36]. Another study concluded that the redundant tissue above a horizontal incision may press on the shaft of the cannula and displace its distal end posteriorly such that it becomes lodged against the posterior wall of the trachea. This does not occur with a vertical incision [37]. In terms of cosmetic appearance, it has been argued that a horizontal skin incision is superior to a vertical skin incision $[38,39]$ and vice versa [40]. Whereas a vertical skin incision is described in many textbooks as the standard procedure, in actual clinical circumstances a horizontal skin incision is favored (36\% vs. $61 \%$, respectively) [41].

\section{A5. How should the thyroid isthmus be managed?}

\section{Recommendation 5}

Thyroid isthmus bisection can improve visualization of the trachea, eliminate constant pressure, and control postoperative bleeding in patients undergoing elective tracheostomy (weak recommendation, low-quality evidence).

There are many approaches to bisecting the thyroid isthmus. According to Kirchner [37], if the thyroid isthmus is retracted downward to open the second and third tracheal rings, after the procedure it can press upward against the shaft of the cannula, displacing the end of the cannula forward against the anterior wall of the trachea. Pressure from the end of the cannula against the anterior tracheal wall, regardless of the cause, may lead to erosion of the innominate artery, especially if there is significant local infection. Kremer et al. [39] also preferred to bisect the thyroid isthmus to avoid damaging the anterior and posterior walls of the trachea and to prevent faulty installation of the cannula into the mediastinum and uncontrolled tissue damage. One study on the management of the thyroid isthmus included both retrospective and prospective cohorts [42]. In the retrospective cohort, bisection of the thyroid isthmus via electrocautery yielded results comparable to those obtained with other techniques (in- cluding suture ligation, clamping, and simple retraction of the thyroid isthmus) in terms of average blood loss, surgical time, and postoperative complications. In the prospective cohort, bisection of the thyroid isthmus using electrocautery was superior in terms of surgical time and comparable in terms of average blood loss and postoperative complications.

\section{A6. What is the preferred method of tracheal incision?}

\section{Recommendation 6}

A Bjork flap can prevent post-tracheostomy tracheal stenosis in patients undergoing elective tracheostomy (weak recommendation, moderate-quality evidence).

Tracheal incision methods include horizontal, vertical, and $\mathrm{H}$ type incisions and a Bjork flap. Several studies have examined the relationship between the type of tracheal incision and posttracheostomy tracheal stenosis. Arcand and Granger [43] found that the frequency and severity of complications were independent of the type of tracheal incision performed. In 1952, Bjork [44] described the creation of an inferiorly based tracheal flap made through the second, third, and fourth rings that was then fixed to the skin with a nonabsorbable suture to secure the tracheostomy lumen. Subsequent comparative studies provided proof of the advantages of the Bjork flap in terms of post-tracheostomy tracheal stenosis. In a retrospective cohort study comparing the degree of post-tracheostomy tracheal stenosis in patients receiving a Bjork flap versus a horizontal or vertical tracheal incision [45], the Bjork flap was associated with a lower rate of stenosis. Another retrospective cohort study compared the Bjork flap with an excision-type window and also showed that the Bjork flap was superior. A prospective cohort study compared the degree of post-tracheostomy tracheal stenosis after a Bjork flap versus a vertical tracheal incision, based on radiologic evaluations [46], and found that use of the Bjork flap was correlated with a lower rate of post-tracheostomy tracheal stenosis.

\section{B. Emergency tracheostomy}

\section{B1. What are the indications for emergency tracheostomy?}

\section{Recommendation 7}

Emergency tracheostomy is indicated in patients with acute airway obstruction who cannot be intubated and in patients in whom endotracheal intubation is expected to fail (strong recommendation, low-quality evidence).

In airway management, adequate oxygenation and ventilation are essential to prevent serious complications and death. Surgical airway management is the final life-saving option for secur- 
ing the airway for oxygenation and ventilation in a "can't intubate, can't oxygenate" situation $[47,48]$. Surgical airway management includes a variety of techniques for securing the airway in patients with acute airway obstructions, including open tracheostomy (surgical visualization and opening of the trachea by positioning a tracheal cannula at the level of the intermediate space between the second and third tracheal rings) [49,50], open cricothyroidotomy (endotracheal cannulation by severing the cricothyroid ligament and tracheal intubation at the larynx) [51,52], percutaneous cricothyroidotomy (endotracheal cannulation via puncture and dilatation of the cricothyroid ligament) [53,54], and percutaneous tracheostomy (endotracheal cannulation via puncture and dilatation of the trachea) $[55,56]$. In the following discussion, emergency tracheostomy serves as the representative surgical airway management technique and includes emergency cricothyroidotomy.

Emergency tracheostomy is rarely necessary because orotracheal intubation is a well-established airway management technique in the emergency setting. However, in rare cases intubation may be unsuccessful or hazardous because of poor visualization of the mouth, pharynx, or larynx due (for example) to hemorrhage or a tumor. In principle, emergency tracheostomy is indicated for patients who cannot be intubated or in whom endotracheal intubation is expected to fail. Emergency tracheostomy is frequently indicated for patients in whom pharyngeal/laryngeal tumors contribute to obstruction of the superior airway. The second-most common indication is deep neck infection, which accounts for $20 \%$ of emergency tracheostomies. Other indications are bilateral vocal fold paralysis, trauma, neck hematoma, airway stenosis, supraglottitis, and supraglottic edema [57-59].

\section{B2. How is emergency tracheostomy performed?}

\section{Recommendation 8}

Emergency tracheostomy is more difficult than elective tracheostomy and has a higher risk of complications. Procedures such as cricothyroidotomy, tracheostomy using a commercial kit, or awake tracheostomy can be attempted to rapidly obtain a safe airway in an emergency setting (weak recommendation, low-quality evidence).

The basic principle of emergency tracheostomy is to secure the airway safely and quickly. Elective tracheostomy can usually be performed under intubation conditions in the operating room, where good lighting, appropriate surgical instruments, and adequate assistance contribute to ensuring that the procedure is safe and effective. However, there is a high probability that appropriate equipment or an experienced practitioner will not be available in an emergency setting. In such cases, there is little consensus regarding the optimal surgical technique for emer- gency tracheostomy, and a wide variety of surgical techniques have been advocated.

Emergency tracheostomy is a challenge for surgeons because patients are usually hypoxic and irritable under local anesthesia. Moreover, it may not be possible to place the patient in the supine position with his or her neck extended. In the first step, the cricoid cartilage and trachea should be quickly identified. When emergency tracheostomy is necessary, a long vertical incision from the cricoid to the trachea provides a good surgical view of the trachea. A bulky tumor may displace the trachea and surrounding structures from their normal anatomical configurations, which makes an emergency tracheostomy in a distressed awake patient even more difficult, even for the most experienced surgeon. Needle aspiration can be helpful in identifying the trachea in patients whose trachea is difficult to find due to head and neck tumors, neck infection, or hematoma [60].

Emergency cricothyroidotomy can be considered to gain emergency surgical access to the airway, as it can be performed much faster than conventional tracheostomy [47,52]. A transverse or vertical incision is made through the skin and cricothyroid membrane $[51,61]$. The main long-term morbidity associated with cricothyroidotomy is the development of subglottic stenosis, so a change to standard tracheostomy within $24-48$ hours is advisable $[58,62]$. Several techniques have been described for emergency cricothyroidotomy, including the rapid four-step technique, bougie-assisted cricothyroidotomy, and the use of cricothyroidotomy scissors [63]; however, evidence of the superiority of one technique over the others is lacking $[47,64]$. All of the techniques include neck extension, identification of the cricothyroid membrane, incision through the skin and cricothyroid membrane, and insertion of an endotracheal cannula [65].

Emergency percutaneous tracheostomy is an alternative method to rapidly obtain an airway in an emergency setting. It can be attempted in a variety of emergency clinical situations requiring rapid access to the airway, similar to open tracheostomy. However, a limitation of percutaneous tracheostomy is that it requires the use of a pre-packaged commercial kit. A comparison between percutaneous and conventional cricothyroidotomy in the placement of an endotracheal tube suggested that the percutaneous approach is superior in terms of speed, especially for the inexperienced practitioner [66]. In conclusion, as there is no standard protocol for emergency tracheostomy, the operator should use the technique with which he or she is most familiar and assess what is required given the clinical situation.

\section{Pediatric tracheostomy}

C1. What are the technical differences between pediatric and adult tracheostomy?

Recommendation 9

(A) A vertical skin incision is preferred in pediatric tracheostomy (weak recommendation, low-quality evidence). 
(B) A vertical tracheal incision without removal of the tracheal cartilage is recommended in pediatric tracheostomy (strong recommendation, low-quality evidence).

(C) Stay sutures are recommended in preparation for decannulation in pediatric patients (strong recommendation, low-quality evidence).

Tracheostomy in pediatric patients is very different from that in adults. The main indications in the pediatric population include congenital anomalies, prematurity, and infection. However, the indications have changed over time. Arcand and Granger [43] compared the period between 1970 and 1975 with that between 1980 and 1985. In the intervening years, the absolute number of pediatric tracheostomies decreased by $84 \%$. Among the indications for tracheostomy, procedures performed for premature birth increased from $28 \%$ to $58 \%$, those for congenital anomalies increased from $6 \%$ to $23 \%$, those for acquired subglottic stenosis increased from $2 \%$ to $23 \%$, and those for neuromuscular disease increased from $9 \%$ to $23 \%$ (a combination of several indications was possible). At the same time, tracheostomy performed for infectious diseases declined from $50 \%$ to $3 \%$. Except in emergency situations, pediatric tracheostomy should be carried out in a surgical environment, with the child under general anesthesia and intubated. The traditional classification of tracheostomy distinguishes between high, middle, and lower tracheostomy with respect to the thyroidal isthmus. Today, middle tracheostomy is the technique of choice. The skin incision may be horizontal or vertical.

In the peer-reviewed literature, most authors recommend a vertical skin incision [39,40,67-69]. Nonetheless, according to a survey of members of the American Society of Pediatric Otolaryngology (ASPO), 61\% of the respondents reported typically using a horizontal incision, with a substantial minority (36\%) preferring a vertical skin incision [41]. The advantages of a vertical incision are that it improves the anatomic orientation and expandability, avoids redundant tissue above and below the tracheostoma, allows easy recannulation in the event of accidental decannulation, and reduces the danger of surface bleeding. The disadvantage is that it causes an unsightly scar. A horizontal incision must be converted to a vertical incision in the lower skin layers to better protect the large vessels of the plexus thyroideus impar and the thyroid gland.

For tracheal fenestration, several markedly different methods have been described, ranging from the use of an inferior stalked cartilage flap to a horizontal or vertical incision. In their 1988 report, Arcand and Granger [43] noted that the frequency and severity of complications were independent of the type of tracheal incision performed. However, the stability of the tracheal wall was jeopardized by creating a window, which could lead to tracheomalacia [70]. Waki et al. [71] recommended the inferior stalked cartilage flap developed in 1960 by Bjork, as it facilitated cannula placement and decreased the risk of pneumomediasti- num. However, the rate of granuloma development in the stoma rose with this method. Fry et al. [72] studied the relationship between the occurrence of various complications and the type of incision. According to the authors, suprastomal collapse and tracheal stenosis were the most important complications, and a vertical incision was far superior to a horizontal H-shaped incision or an inferior stalked cartilage flap. The occurrence of tracheal stenosis in patients treated with the flap was significant.

The placement of stay sutures alongside a vertical tracheal incision is the most commonly practiced method of managing accidental decannulation, including in pediatric tracheostomy $[40,73,74]$. In the event of accidental decannulation, stay sutures allow the tracheostoma to be pulled open and towards the skin surface, thereby facilitating recannulation. Stay sutures can also overcome some of the difficulties related to an urgent tracheostomy tube change in the event of recalcitrant mucus plugging during the early postoperative period. According to the ASPO survey, the use of stay sutures was prevalent among pediatric otolaryngologists, with $94 \%$ reporting their consistent use, only 3\% reporting their occasional use, and another 3\% reporting that they were never used [41].

\section{$\mathrm{C} 2$. What are the selection criteria in choosing an appropriate cannula in pediatric patients?}

\section{Recommendation 10}

(A) The tube size, and especially the tube diameter, should be chosen based on the age of the patient (strong recommendation, low-quality evidence).

(B) The length and curvature of the tube should be considered in selecting an appropriate tracheostomy tube (strong recommendation, low-quality evidence).

(C) Cuffed tracheostomy tubes are not generally recommended for children unless there is a need for high-pressure ventilation or the child is at high risk of aspiration (strong recommendation, low-quality evidence).

The selection of an appropriately sized tracheostomy tube is critical for the success of the procedure and the prevention of complications [75]. Typically, the tube size, and specifically the tube diameter, should be chosen based on the patient's age. However, this general rule does not apply when, for example, the size of the patient is inconsistent with his or her chronological age. The size of the tracheostomy incision in relation to the airway is partially determined by the underlying problem. A child in whom a tracheostomy is performed to prevent chronic aspiration may require a tube that is larger than the diameter of the airway, whereas a child who requires nocturnal ventilation but who plugs the tracheostomy opening during the day may do well with a much smaller diameter tube. Considerations related to the diameter of the tracheostomy tube include tracheal size and shape, the indi- 
cations for tracheostomy, lung mechanics, upper airway resistance, and the needs of the child for speech, ventilation, and airway clearance. Other factors that must be taken into account are the length, curvature, flexibility, and composition of the tube.

The tracheostomy tube must fit both the airway and the functional needs of the patient. It must have the appropriate shape and length to remain securely in the airway, without undue pressure on any portion of the neck or trachea. In most cases, the tube should extend at least $2 \mathrm{~cm}$ beyond the stoma and no closer than 1-2 cm to the carina. The tube's diameter should be selected so as to avoid damage to the tracheal wall, minimize the work of breathing, and, when possible, promote translaryngeal airflow. The tube's curvature should be such that the distal portion is concentric and collinear with the trachea. An assessment of the appropriate curvature should be confirmed via neck/chest radiographs or flexible bronchoscopy [76].

Other decisions include whether the tracheostomy tube should be cuffed or non-cuffed, or fenestrated or non-fenestrated. Under most circumstances, uncuffed tracheostomy tubes are preferred, as the indications for cuffed tracheostomy tubes in pediatrics are limited. Cuffed tubes may be used to minimize the risk of aspiration and in patients requiring mechanical or nocturnal ventilation. In the latter, the cuff is inflated at night for ventilation and deflated during the day to facilitate speech. When a cuffed tracheostomy tube is employed, a distinction must be made between a high-volume/low-pressure and a low-volume/high-pressure cuff. When a low-pressure/high-volume cuff is employed, pressure in the cuff is kept as low as possible. Generally, cuff pressures $<20 \mathrm{~cm}$ $\mathrm{H}_{2} \mathrm{O}$ are well-tolerated, as higher pressures decrease perfusion of the airway epithelium [77]. Experience indicates that fenestrated tracheostomy tubes aid speech by enhancing translaryngeal air flow. They may also increase translaryngeal secretion clearance. However, according to a European experience, tracheostomy tubes with multiple small fenestrations along their sides promote the development of granulation tissue in the area of the fenestration [76]. Consequently, the use of fenestrated tracheostomy tubes in pediatric patients is the exception rather than the rule.

\section{Mediastinal tracheostomy \\ D1. What are the indications for mediastinal tracheostomy?}

\section{Recommendation 11}

(A) The indications for mediastinal tracheostomy are malignant lesions involving both the larynx and upper trachea, stomal recurrence after previous laryngectomy for carcinoma, or a tumor involving the upper esophagus (weak recommendation, low-quality evidence).

(B) A mediastinal tracheostomy can be performed in selected patients with benign conditions such as tracheal stenosis, tracheoesophageal fistula, and tracheal necrosis (weak recommendation, low-quality evidence).
A mediastinal tracheostomy consists of subtotal excision of the trachea and the construction of a skin tube that passes through the mediastinum and is anastomosed with the remaining trachea. Indications for mediastinal tracheostomy are malignant lesions involving both the larynx and upper trachea, stomal recurrence after previous laryngectomy for carcinoma, or a tumor involving the upper esophagus [78,79]. In benign disease, mediastinal tracheostomies are rarely performed; instead, the main indications are stomal stenosis after laryngectomy, complications from high-dose radiation therapy, tracheogastric fistulas following laryngopharyngoesophagectomy and gastric pull-up, traumatic tracheoesophageal fistulas after tracheostomy, and postoperative tracheal necrosis after laryngopharyngoesophagectomy and standard cervical tracheostomy.

Mediastinal tracheostomy was previously associated with high mortality. In the series studied by Terz et al. [78], the mortality rate after mediastinal tracheostomy was 33\%-50\%, with postoperative rupture of the innominate artery as the main cause of death. However, following advances in operative techniques and patient care, the mortality rate has been reduced to $7 \%-18 \%$. Nonetheless, the complications of mediastinal tracheostomy may be fatal. They are usually related to pressure necrosis of the innominate artery caused by the trachea, tracheostoma separation caused by tension suture leading to exposure of the great vessels (particularly in patients with a prior history of radiation therapy), and persistence of a dead space in the upper mediastinum, which can be a cause of mediastinitis or a mediastinal abscess $[80,81]$.

\section{D2. What types of additional procedures are needed for medi- astinal tracheostomy?}

\section{Recommendation 12}

(A) Relocation of the trachea inferior to the innominate artery can reduce the tension around the tracheal stoma (strong recommendation, low-quality evidence).

(B) A muscle flap, such as a pectoralis major or omental flap, can be created to fill the dead space in the upper mediastinum and protect the major vessels as well as the tracheal stoma (strong recommendation, low-quality evidence).

Preventing the fatal complications of mediastinal tracheostomy may require additional procedures. To avoid close contact between the tracheal stump and the innominate artery, Waddell and Cannon [81] proposed relocating the inferior trachea to the innominate artery. To avoid mediastinal dead space, Grillo performed a breastplate resection including the manubrium, medial clavicles, and costal cartilages of the first and second ribs bilaterally. To reduce tension on the trachea-cutaneous anastomosis, Grillo constructed a stoma using a large bipedicled flap from 
thoracic skin (thoracic apron flap) elevated from the pectoral fascia and inserted into the mediastinal defect. In some cases, the pedicled omental flap can be placed around the vascular structures and sutured onto the vessels to protect them.

\section{E. Decannulation}

E1. What are the indications for decannulation of a tracheostomy tube?

\section{Recommendation 13}

(A) Decannulation should be considered in patients whose upper airway obstruction has been resolved and airway secretions are controlled (strong recommendation, lowquality evidence).

(B) Decannulation should be performed when mechanical ventilation is no longer needed (strong evidence, lowquality evidence).

(C) The decision to perform decannulation should be made according to the reason for the tracheostomy (weak recommendation, low-quality evidence).

(D) Laryngoscopy or bronchoscopy is necessary to evaluate vocal cord movement and airway obstruction (strong recommendation, low-quality evidence).

Decannulation of a tracheostomy tube should be considered in patients whose upper airway obstruction has been resolved, whose airway secretions can be expectorated by coughing, and when mechanical ventilation is no longer needed $[82,83]$. An additional requirement for tracheostomy removal is that the patient's hemodynamics are stable [84].

The timing of decannulation of a tracheostomy tube differs between patients with acute airway obstruction and those with long-term tube placement. In the former, prompt decannulation can be performed when the airway obstruction is resolved [82]. Patients undergoing tracheostomy for maxillofacial and laryngotracheal trauma have higher decannulation rates and a shorter time to decannulation than patients with cardiopulmonary and neurological indications [85]. For patients with a prolonged tracheostomy, the risk factors of impaired respiration should be resolved, including medical comorbidities and respiratory drive issues. Decannulation failure is defined as the need to reinsert the tracheostomy tube within 48-96 hours after its removal [86]. The most common reason for decannulation failure is ineffective coughing and sputum retention [87].

The airway should be evaluated using flexible nasopharyngolaryngoscopy or bronchoscopy prior to decannulation [88]. Glottic closure and vocal cord movement should be determined, and there should be no aspiration related to vocal cord movement [89].

\section{E2. How is decannulation performed?}

\section{Recommendation 14}

(A) Admission for a 24-hour capping trial (deflated-cuff tracheostomy occlusion) with continuous pulse oximetry monitoring is necessary before decannulation (strong recommendation, low-quality evidence).

(B) The tracheostomy tube in adult patients should be downsized to a tube with an inner diameter of $\leq 6 \mathrm{~mm}$ (weak recommendation, low-quality evidence).

(C) Decannulation should be performed when the $\mathrm{SaO}_{2}$ is $>90 \%$ and the $\mathrm{PaCO}_{2}$ is $<60 \mathrm{mmHg}$ (strong recommendation, low-quality evidence).

(D) During a "physiological decannulation" trial, cough effectiveness, swallowing, voice quality, and the patient's ability to adequately breathe through the upper airway should be monitored (weak recommendation, low-quality evidence).

The ability to tolerate tube capping for $>24$ hours is a prerequisite for decannulation [90-92], although some studies recommend a longer period ranging from 48 to 72 hours [90,91]. Admission is recommended for the occlusion test [85]. In adult patients, the tracheostomy tube should be downsized for 4 days to a tube with an inner diameter of $\leq 6 \mathrm{~mm}$ [84]. Most studies recommend decannulation when the $\mathrm{SaO}_{2}$ is $>90 \%$ [87,93,94], but Bach and Saporito [95] recommended a stricter cutoff value of $>92 \%$, and Pasqua et al. [96] a $\mathrm{PaO}_{2} / \mathrm{FiO}_{2}$ of $>200$.

Based on arterial blood gas analyses, Ceriana et al. [84] decannulated patients with a $\mathrm{pH}>7.35$, an increase in $\mathrm{PaCO}_{2}$ of $<5 \%$, and a $\mathrm{PaCO}_{2}$ value $<60 \mathrm{mmHg}$. During a "physiological decannulation" trial, cough effectiveness, swallowing, voice quality, and the patient's ability to adequately breathe through the upper airway should be monitored [82]. Effective coughing and spontaneous expectoration (the need for two or fewer suctions per day) are necessary before decannulation [89]. Effective coughing can be defined as the absence of a need for suctioning, maximal expiratory pressure $\geq 40 \mathrm{~cm} \mathrm{H}_{2} \mathrm{O}$, or cough peak flow $>160 \mathrm{~L} / \mathrm{min}[84,92,97]$. Swallowing function should be confirmed to avoid aspiration and can be assessed via fibroendoscopic evaluation during liquid and food administration, by evaluating the gag reflex in a blue dye test, or via video-fluoroscopy [97].

\section{F. Postoperative management}

F1. When should the tracheostomy tube first be changed?

\section{Recommendation 15}

As a mature stomal tract generally forms at 3 days after the tracheostomy, the first tube change should not be performed 
during that time. Ideally, the first tube change is performed 7-10 days later, by an experienced physician (weak recommendation, low-quality evidence).

Postoperative care, including tube changes, is routine in most cases; however, an inadequate frequency of tube changes in the early postoperative period may result in airway loss and significant morbidity, most commonly pneumomediastinum or cardiopulmonary arrest. If a tube change is performed in an immature stomal tract, the tube may be accidentally dislodged, or if it is intentionally removed, attempting to replace it may result in false passage to the mediastinum [98]. Therefore, the first tracheostomy tube change should be performed when the stomal tract has formed. Although there is no established evidence, previous reports suggest that the first tube replacement should occur at 3-14 days after the tracheostomy, as in most patients this is sufficient to allow the formation of a stable endotracheal-cutaneous tract [99-101]. A tube change within the first 72 hours should be avoided unless the cuff has been damaged or a tracheostomy tube of a different size or shape is found to be necessary. To prevent accidental complications, the first tube replacement should be done by two medical personnel, one of whom is an experienced physician. Furthermore, not removing the skin or stay suture can be considered, as well as specific interventions such as the use of a fiberoptic endoscope, tube change stylet, or guidewire [102].

\section{F2. What is the appropriate postoperative care after tracheosto- my?}

\section{Recommendation 16}

(A) The type and size of the tube should be selected according to the patient's condition after tracheostomy (weak recommendation, low-quality evidence).

(B) A post-tracheostomy chest X-ray may be appropriate for high-risk patients with postoperative complications (weak recommendation, low-quality evidence).

(C) Adequate humidification and suction are needed for the postoperative care of patients unable to expectorate their secretions (weak recommendation, low-quality evidence).

Postoperative care after tracheostomy includes appropriate selection of the tracheostomy tube, postoperative evaluation, adequate humidification, and secretion removal. After a tracheostomy, a tube of appropriate type and size should be chosen according to the patient's condition. The angle and length of the tube should be collinear with the patient's trachea. A cuff tube is used for patients who are on a ventilator during the immediate postoperative period and for those at risk of aspiration. The cuff pressure should be kept below $20-25 \mathrm{mmHg}$ to maintain capil- lary perfusion of the tracheal mucosa, because excessive expansion of the cuff may cause tracheal mucosal damage and necrosis $[99,103]$.

Routine post-tracheostomy chest X-rays have been used to exclude postoperative complications such as pneumothorax, pneumomediastinum, tube malposition, atelectasis, and subcutaneous emphysema [104]. However, a systemic review reported that routine post-tracheostomy chest X-rays are not very informative, with findings that have a limited impact on patient management. The complication detection rates for surgical and percutaneous tracheostomy are $2.2 \%$ and $3.2 \%$, respectively [105]. Nevertheless, post-tracheostomy chest X-rays may be valuable in patients at higher risk of complications, such as those with postoperative signs and symptoms of complications or who underwent an emergent or "difficult" tracheostomy.

In tracheotomized patients, a lack of humidity in the inhaled air may cause airway changes such as mucosal damage, loss of mucociliary transport, and thickening of secretions. Furthermore, access to humidified air is strongly recommended for patients who require ventilation and those with large quantities of tracheal secretions [102].

Routine suctioning of the tracheostomy tube is not necessary. The frequency of suctioning depends on the presence of sputum in the patient's airway. If the patient is unable to cough out the secretions, the removal of secretions from the tube by suctioning is recommended. Suctioning should be performed aseptically, and its frequency along with the appropriate catheter insertion depth should be determined based on the patient's secretions.

\section{G. Percutaneous dilatational tracheostomy G1. When should PDT be performed for patients in the ICU?}

\section{Recommendation 17}

In patients undergoing prolonged mechanical ventilation, the appropriate timing of PDT should be determined individually and depends on the clinical condition of the patient (weak recommendation, low-quality evidence).

In previous studies, early tracheostomy was defined as a tracheostomy performed at 2-10 days from the start of mechanical ventilation [106-109]. Several studies have shown that, compared with prolonged translaryngeal intubation, tracheostomy decreases the incidence of ventilator-associated pneumonia (VAP), the duration of mechanical ventilation, and the length of stay in the ICU $[15,110]$. The outcomes of early versus late tracheostomy have been compared in numerous single- and multicenter studies and in a meta-analysis [15,106,110-114]. However, conflicting results were obtained regarding the prognosis. A recent meta-analysis reported that early tracheostomy does not significantly alter mortality, the incidence of VAP, duration of 
mechanical ventilation, or length of stay in the ICU [112]. Based on these results and the above-cited studies, a general recommendation regarding the optimal timing of tracheostomy cannot be made because supportive evidence is lacking. Instead, the timing should be determined individually, depending on the clinical assessment.

G2. Which is the appropriate procedure for patients who need tracheostomy, PDT or surgical tracheostomy?

\section{Recommendation 18}

PDT is recommended as the tracheostomy procedure of choice in critically ill patients undergoing prolonged mechanical ventilation (weak recommendation, low-quality evidence).

In the ICU, PDT is generally preferred over surgical tracheostomy (ST), because it can be performed more easily there, and the problems that may occur when a ventilated patient is transferred to the operating room can be avoided. For both PDT and ST, clinically important complications are rare, and fatal complications, such as uncontrolled bleeding or airway loss, have been reported only in retrospective studies or case reports $[115,116]$. Although no large, well-conducted RCTs have addressed PDTrelated complications, previous studies reported that there were fewer or equally few complications when PDT was performed compared to when ST was performed [117-119]. Additionally, the financial cost of PDT is lower than that of ST in the operating room [120]. Accordingly, PDT in the ICU should be considered as the procedure of choice for tracheostomy. Further research on the long-term prognosis of PDT versus that of ST is needed.

\section{CONFLICT OF INTEREST}

No potential conflict of interest relevant to this article was reported.

\section{ORCID}

Inn-Chul Nam
Yoo Seob Shin
Woo-Jin Jeong
MinWoo Park
Seong Yong Park
Chang Myeon Song
Young Chan Lee
Jae Hyun Jeon
Jongmin Lee
https://orcid.org/0000-0001-9246-1047 https://orcid.org/0000-0002-2007-1100 https://orcid.org/0000-0001-8577-6964 https://orcid.org/0000-0001-5611-4187 https://orcid.org/0000-0002-5180-3853 https://orcid.org/0000-0001-5267-0135 https://orcid.org/0000-0001-5577-7288 https://orcid.org/0000-0003-3582-3165 https://orcid.org/0000-0002-0165-5856
Chang Hyun Kang ～https://orcid.org/0000-0002-1612-1937

Il-Seok Park https://orcid.org/0000-0001-8143-8968

Kwhanmien Kim https://orcid.org/0000-0002-6581-2750

Dong Il Sun https://orcid.org/0000-0001-9950-568X

\section{AUTHOR CONTRIBUTIONS}

Conceptualization: DIS, KK. Data curation: ICN, YSS, WJJ, MWP, SYP, CMS, YCL, JHJ, JL. Formal analysis: ISP, CHK. Methodology: ISP, CHK. Visualization: ICN. Writing-original draft: ICN, YSS, WJJ, MWP, SYP, CMS, YCL, JHJ, JL. Writing-review \& editing: all authors.

\section{SUPPLEMENTARY MATERIALS}

Supplementary materials can be available at https://doi.org/10. 21053/ceo.2020.00353.

\section{REFERENCES}

1. Al-Ansari MA, Hijazi MH. Clinical review: percutaneous dilatational tracheostomy. Crit Care. 2006 Feb;10(1):202.

2. Durbin CG Jr. Tracheostomy: why, when, and how? Respir Care. 2010 Aug;55(8):1056-68.

3. Mehta AB, Syeda SN, Bajpayee L, Cooke CR, Walkey AJ, Wiener RS. Trends in tracheostomy for mechanically ventilated patients in the United States, 1993-2012. Am J Respir Crit Care Med. 2015 Aug;192(4):446-54.

4. Mitchell RB, Hussey HM, Setzen G, Jacobs IN, Nussenbaum B, Dawson C, et al. Clinical consensus statement: tracheostomy care. Otolaryngol Head Neck Surg. 2013 Jan;148(1):6-20.

5. Kim SY, Park JE, Lee YJ, Seo HJ, Sheen SS, Hahn S, et al. Testing a tool for assessing the risk of bias for nonrandomized studies showed moderate reliability and promising validity. J Clin Epidemiol. 2013 Apr;66(4):408-14.

6. Shea BJ, Grimshaw JM,Wells GA, Boers M,Andersson N, Hamel C, et al. Development of AMSTAR: a measurement tool to assess the methodological quality of systematic reviews. BMC Med Res Methodol. 2007 Feb;7:10.

7. Qaseem A, SnowV, Owens DK, Shekelle P; Clinical Guidelines Committee of the American College of Physicians. The development of clinical practice guidelines and guidance statements of the American College of Physicians: summary of methods. Ann Intern Med. 2010 Aug;153(3):194-9.

8. Guyatt G, Gutterman D, Baumann MH, Addrizzo-Harris D, Hylek EM, Phillips B, et al. Grading strength of recommendations and quality of evidence in clinical guidelines: report from an American college of chest physicians task force. Chest. 2006 Jan;129(1):174-81.

9. American Society of Anesthesiologists Task Force on Management of the Difficult Airway. Practice guidelines for management of the difficult airway: an updated report by the American Society of Anesthesiologists Task Force on Management of the Difficult Airway. Anesthesiology. 2003 May;98(5):1269-77.

10. Wong DT, Prabhu AJ, Coloma M, Imasogie N, Chung FF. What is the minimum training required for successful cricothyroidotomy?: a study in mannequins. Anesthesiology. 2003 Feb;98(2):349-53. 
11. Esteban A, Anzueto A, Alia I, Gordo F, Apezteguia C, Palizas F, et al. How is mechanical ventilation employed in the intensive care unit? An international utilization review. Am J Respir Crit Care Med. 2000 May;161(5):1450-8.

12. Stauffer JL, Olson DE, Petty TL. Complications and consequences of endotracheal intubation and tracheotomy: a prospective study of 150 critically ill adult patients. Am J Med. 1981 Jan;70(1):65-76.

13. Diaz-Prieto A, Mateu A, Gorriz M, Ortiga B, Truchero C, Sampietro $\mathrm{N}$, et al. A randomized clinical trial for the timing of tracheotomy in critically ill patients: factors precluding inclusion in a single center study. Crit Care. 2014 Oct;18(5):585.

14. Dunham CM, LaMonica C. Prolonged tracheal intubation in the trauma patient. JTrauma. 1984 Feb;24(2):120-4.

15. Rumbak MJ, Newton M,TruncaleT, Schwartz SW, Adams JW, Hazard PB. A prospective, randomized, study comparing early percutaneous dilational tracheotomy to prolonged translaryngeal intubation (delayed tracheotomy) in critically ill medical patients. Crit Care Med. 2004 Aug;32(8):1689-94.

16. Trouillet JL, Luyt CE, Guiguet M, Ouattara A, Vaissier E, Makri R, et al. Early percutaneous tracheotomy versus prolonged intubation of mechanically ventilated patients after cardiac surgery: a randomized trial.Ann Intern Med. 2011 Mar;154(6):373-83.

17. Zheng Y, Sui F, Chen XK, Zhang GC,Wang XW, Zhao S, et al. Early versus late percutaneous dilational tracheostomy in critically ill patients anticipated requiring prolonged mechanical ventilation. Chin Med J (Engl). 2012 Jun;125(11):1925-30.

18. Gomes Silva BN, Andriolo RB, Saconato H, Atallah AN, Valente O. Early versus late tracheostomy for critically ill patients. Cochrane Database Syst Rev. 2012 Mar;(3):CD007271.

19. Liu CC, Livingstone D, Dixon E, Dort JC. Early versus late tracheostomy: a systematic review and meta-analysis. Otolaryngol Head Neck Surg. 2015 Feb;152(2):219-27.

20. Siempos II, Ntaidou TK, Filippidis FT, Choi AM. Effect of early versus late or no tracheostomy on mortality and pneumonia of critically ill patients receiving mechanical ventilation: a systematic review and meta-analysis. Lancet Respir Med. 2015 Feb;3(2):150-8.

21. Adly A, YoussefTA, El-Begermy MM, Younis HM.Timing of tracheostomy in patients with prolonged endotracheal intubation: a systematic review. Eur Arch Otorhinolaryngol. 2018 Mar;275(3):679-90.

22. Raimondi N,Vial MR, Calleja J, Quintero A, Cortes A, Celis E, et al. Evidence-based guidelines for the use of tracheostomy in critically ill patients. J Crit Care. 2017 Apr;38:304-18.

23. Ben-Avi R, Ben-Nun A, Levin S, Simansky D, Zeitlin N, Sternik L, et al. Tracheostomy after cardiac surgery: timing of tracheostomy as a risk factor for mortality. J Cardiothorac Vasc Anesth. 2014 Jun; 28(3):493-6.

24. Bickenbach J, Fries M, Offermanns V, Von Stillfried R, Rossaint R, Marx G, et al. Impact of early vs. late tracheostomy on weaning: a retrospective analysis. Minerva Anestesiol. 2011 Dec;77(12):117683.

25. Devarajan J,Vydyanathan A, Xu M, Murthy SM, McCurry KR, Sessler DI, et al. Early tracheostomy is associated with improved outcomes in patients who require prolonged mechanical ventilation after cardiac surgery. J Am Coll Surg. 2012 Jun;214(6):1008-16.

26. Hosseinian L, Chiang Y, Itagaki S, Polanco A, Rhee A, Chikwe J. Earlier versus later tracheostomy in patients with respiratory failure after cardiac surgery in the United States. J Cardiothorac Vasc Anesth. 2014 Jun;28(3):488-92.

27. Huang YH, Lee TC, Liao CC, Deng YH, Kwan AL. Tracheostomy in craniectomised survivors after traumatic brain injury: a cross-sectional analytical study. Injury. 2013 Sep;44(9):1226-31.

28. Mahafza T, Batarseh S, Bsoul N, Massad E, Qudaisat I,Al-Layla AE. Early vs. late tracheostomy for the ICU patients: experience in a referral hospital. Saudi J Anaesth. 2012 Apr;6(2):152-4.
29. Puentes W, Jerath A, Djaiani G, Cabrerizo Sanchez R, Wasowicz M. Early versus late tracheostomy in cardiovascular intensive care patients. Anaesthesiol Intensive Ther. 2016;48(2):89-94.

30. Villwock JA, Jones K. Outcomes of early versus late tracheostomy: 2008-2010. Laryngoscope. 2014 Aug;124(8):1801-6.

31. Wang HK, Lu K, Liliang PC, Wang KW, Chen HJ, Chen TB, et al. The impact of tracheostomy timing in patients with severe head injury: an observational cohort study. Injury. 2012 Sep;43(9):1432-6.

32. Oliver ER, Gist A, Gillespie MB. Percutaneous versus surgical tracheotomy: an updated meta-analysis. Laryngoscope. 2007 Sep; 117(9):1570-5.

33. Wang SJ, Sercarz JA, Blackwell KE, Aghamohammadi M, Wang MB. Open bedside tracheotomy in the intensive care unit. Laryngoscope. 1999 Jun;109(6):891-3.

34. Yoo DB, Schiff BA, Martz S, Fraioli RE, Smith RV, Kvetan V, et al. Open bedside tracheotomy: impact on patient care and patient safety. Laryngoscope. 2011 Mar;121(3):515-20.

35. Durbin CG Jr. Early complications of tracheostomy. Respir Care. 2005 Apr;50(4):511-5.

36. Dukes HM.Tracheostomy.Thorax. 1970 Sep;25(5):573-6.

37. Kirchner JA. Avoiding problems in tracheotomy. Laryngoscope. 1986 Jan;96(1):55-7.

38. Fraga JC, Souza JC, Kruel J. Pediatric tracheostomy. J Pediatr (Rio J). 2009 Mar-Apr;85(2):97-103.

39. Kremer B, Botos-Kremer AI, Eckel HE, Schlondorff G. Indications, complications, and surgical techniques for pediatric tracheostomies: an update. J Pediatr Surg. 2002 Nov;37(11):1556-62.

40. Hotaling AJ, Robbins WK, Madgy DN, Belenky WM. Pediatric tracheotomy: a review of technique.Am J Otolaryngol. 1992 Mar-Apr; 13(2):115-9.

41. Ruggiero FP, Carr MM. Infant tracheotomy: results of a survey regarding technique. Arch Otolaryngol Head Neck Surg. 2008 Mar; 134(3):263-7.

42. Calhoun KH, Weiss RL, Scott B, Guendert D, Hokanson JA. Management of the thyroid isthmus in tracheostomy: a prospective and retrospective study. Otolaryngol Head Neck Surg. 1994 Oct;111(4): 450-2.

43. Arcand P, Granger J. Pediatric tracheostomies: changing trends. J Otolaryngol. 1988 Apr;17(2):121-4.

44. Bjork VO. Partial resection of the only remaining lung with the aid of respirator treatment. J Thorac Cardiovasc Surg. 1960 Feb;39: 179-88.

45. Li M, Yiu Y, Merrill T, Yildiz V, deSilva B, Matrka L. Risk factors for posttracheostomy tracheal stenosis. Otolaryngol Head Neck Surg. 2018 Oct;159(4):698-704.

46. Lulenski GC. Long-term tracheal dimensions after flap tracheostomy. Arch Otolaryngol. 1981 Feb;107(2):114-6.

47. Frerk C, Mitchell VS, McNarry AF, Mendonca C, Bhagrath R, Patel A, et al. Difficult Airway Society 2015 guidelines for management of unanticipated difficult intubation in adults. Br J Anaesth. 2015 Dec;115(6):827-48.

48. Pracy JP, Brennan L, Cook TM, Hartle AJ, Marks RJ, McGrath BA, et al. Surgical intervention during a Can't Intubate Can't Oxygenate (CICO) event: Emergency Front-of-neck Airway (FONA)? Clin Otolaryngol. 2016 Dec;41(6):624-6.

49. Bonanno FG. Techniques for emergency tracheostomy. Injury. 2008 Mar;39(3):375-8.

50. Golden GT, Fox JW, Edlich RF, Edgerton MT. Emergency tracheostomy.Am J Surg. 1976 Jun;131(6):766-7.

51. McNiven ND, Pracy JP, McGrath BA, Robson AK. The role of Scalpel-bougie cricothyroidotomy in managing emergency Front of Neck Airway access: a review and technical update for ENT surgeons. Clin Otolaryngol. 2018 Jun;43(3):791-4.

52. Melchiors J,Todsen T, Konge L, Charabi B, von Buchwald C. Crico- 
thyroidotomy: the emergency surgical airway. Head Neck. 2016 Jul;38(7):1129-31.

53. Dimitriadis JC, Paoloni R. Emergency cricothyroidotomy: a randomised crossover study of four methods. Anaesthesia. 2008 Nov; 63(11):1204-8.

54. Murphy C, Rooney SJ, Maharaj CH, Laffey JG, Harte BH. Comparison of three cuffed emergency percutaneous cricothyroidotomy devices to conventional surgical cricothyroidotomy in a porcine model. Br J Anaesth. 2011 Jan;106(1):57-64.

55. Davidson SB, Blostein PA, Walsh J, Maltz SB, VandenBerg SL. Percutaneous tracheostomy: a new approach to the emergency airway. J Trauma Acute Care Surg. 2012 Aug;73(2 Suppl 1):S83-8.

56. Kincade RC, Cooper JR Jr. Emergency percutaneous tracheostomy after unsuccessful orotracheal intubation in a patient with an acute myocardial infarction. Tex Heart Inst J. 2004;31(2):184-5.

57. Altman KW, Waltonen JD, Kern RC. Urgent surgical airway intervention: a 3 year county hospital experience. Laryngoscope. 2005 Dec;115(12):2101-4.

58. Costa L, Matos R, Julio S, Vales F, Santos M. Urgent tracheostomy: four-year experience in a tertiary hospital.World J Emerg Med. 2016; 7(3):227-30

59. Yuen HW, Loy AH, Johari S. Urgent awake tracheotomy for impending airway obstruction. Otolaryngol Head Neck Surg. 2007 May; 136(5):838-42.

60. Chin BS, Sabin S, Erickson A, Ghosh BC. Emergency tracheostomy for advanced head and neck tumor. J Surg Oncol. 1998 Jan;67(1): 49-51.

61. Helm M, Hossfeld B, Jost C, Lampl L, Bockers T. Emergency cricothyroidotomy performed by inexperienced clinicians: surgical technique versus indicator-guided puncture technique. Emerg Med J. 2013 Aug;30(8):646-9.

62. Uehara M, Kokuryo S, Sasaguri M, Tominaga K. Emergency cricothyroidotomy for difficult airway management after asynchronous bilateral neck dissections: a case report and literature review. J Oral Maxillofac Surg. 2015 Oct;73(10):2066.

63. King W,Teare J,VandrevalaT, Cartwright S, Mohammed KB, Patel B. Evaluation of a novel Surgicric ${ }^{\circledR}$ cricothyroidotomy device for emergency tracheal access in a porcine model. Anaesthesia. 2016 Feb; 71(2):177-84

64. Kanji H,Thirsk W, Dong S, Szava-Kovats M,Villa-Roel C, Singh M, et al. Emergency cricothyroidotomy: a randomized crossover trial comparing percutaneous techniques: classic needle first versus "incision first". Acad Emerg Med. 2012 Sep;19(9):E1061-7.

65. Paix BR, Griggs WM. Emergency surgical cricothyroidotomy: 24 successful cases leading to a simple 'scalpel-finger-tube' method. Emerg Med Australas. 2012 Feb;24(1):23-30.

66. Chrisman L, King W, Wimble K, Cartwright S, Mohammed KB, Patel B. Surgicric 2: a comparative bench study with two established emergency cricothyroidotomy techniques in a porcine model. Br J Anaesth. 2016 Aug;117(2):236-42.

67. Gerson CR, Tucker GF Jr. Infant tracheotomy. Ann Otol Rhinol Laryngol. 1982 Jul-Aug;91(4 Pt 1):413-6.

68. Lewis CW, Carron JD, Perkins JA, Sie KC, Feudtner C. Tracheotomy in pediatric patients: a national perspective. Arch Otolaryngol Head Neck Surg. 2003 May;129(5):523-9.

69. Solares CA, Krakovitz P, Hirose K, Koltai PJ. Starplasty: revisiting a pediatric tracheostomy technique. Otolaryngol Head Neck Surg. 2004 Nov;131(5):717-22.

70. Hauser F. Tracheomalacie nach Tracheotomie. Ann Paediatr. 1949 Jan;172(1):70.

71. Waki EY, Madgy DN, Zablocki H, Belenky WM, Hotaling AJ. An analysis of the inferior based tracheal flap for pediatric tracheotomy. Int J Pediatr Otorhinolaryngol. 1993 May;27(1):47-54.

72. Fry TL, Jones RO, Fischer ND, Pillsbury HC. Comparisons of tra- cheostomy incisions in a pediatric model. Ann Otol Rhinol Laryngol. 1985 Sep-Oct;94(5 Pt 1):450-3

73. Carron JD, Derkay CS, Strope GL, Nosonchuk JE, Darrow DH. Pediatric tracheotomies: changing indications and outcomes. Laryngoscope. $2000 \mathrm{Jul} ; 110$ (7):1099-104.

74. Lee SH, Kim KH, Woo SH. The usefulness of the stay suture technique in tracheostomy. Laryngoscope. 2015 Jun;125(6):1356-9.

75. Campisi P, ForteV. Pediatric tracheostomy. Semin Pediatr Surg. 2016 Jun;25(3):191-5.

76. Sherman JM, Davis S, Albamonte-Petrick S, Chatburn RL, Fitton C, Green C, et al. Care of the child with a chronic tracheostomy. Am J Respir Crit Care Med. 2000 Jan;161(1):297-308.

77. Stenqvist O, Bagge U. Cuff pressure and microvascular occlusion in the tracheal mucosa: an intravital microscopic study in the rabbit. Acta Otolaryngol. 1979;88(5-6):451-4.

78. Terz JJ,Wagman LD, King RE, Brown P, Neifeld JP, LawrenceW Jr. Results of extended resection of tumors involving the cervical part of the trachea. Surg Gynecol Obstet. 1980 Oct;151(4):491-6.

79. Wurtz A, De Wolf J. Anterior mediastinal tracheostomy: past, present, and future. Thorac Surg Clin. 2018 Aug;28(3):277-84.

80. Sisson GA, Straehley CJ Jr, Johnson NE. Mediastinal dissection for recurrent cancer after laryngectomy. Laryngoscope. 1962 Aug;72: 1064-77.

81. Waddell WR, Cannon B. A technic for subtotal excision of the trachea and establishment of a sternal tracheostomy. Ann Surg. 1959 Jan;149(1):1-8

82. Christopher KL. Tracheostomy decannulation. Respir Care. 2005 Apr;50(4):538-41.

83. O'Connor HH, White AC. Tracheostomy decannulation. Respir Care. 2010 Aug;55(8):1076-81.

84. Ceriana P, Carlucci A, Navalesi P, Rampulla C, Delmastro M, Piaggi $\mathrm{G}$, et al. Weaning from tracheotomy in long-term mechanically ventilated patients: feasibility of a decisional flowchart and clinical outcome. Intensive Care Med. 2003 May;29(5):845-8.

85. Funamura JL, Durbin-Johnson B, Tollefson TT, Harrison J, Senders $\mathrm{CW}$. Pediatric tracheotomy: indications and decannulation outcomes. Laryngoscope. 2014 Aug;124(8):1952-8.

86. Santus P, Gramegna A, Radovanovic D, Raccanelli R, Valenti V, Rabbiosi $\mathrm{D}$, et al. A systematic review on tracheostomy decannulation: a proposal of a quantitative semiquantitative clinical score. BMC Pulm Med. 2014 Dec;14:201.

87. Choate K, Barbetti J, Currey J.Tracheostomy decannulation failure rate following critical illness: a prospective descriptive study. Aust Crit Care. 2009 Feb;22(1):8-15.

88. Alvo A, Olavarria C. Decannulation and assessment of deglutition in the tracheostomized patient in non-neurocritical intensive care. Acta Otorrinolaringol Esp. 2014 Mar-Apr;65(2):114-9.

89. Hiss SG, Postma GN. Fiberoptic endoscopic evaluation of swallowing. Laryngoscope. 2003 Aug;113(8):1386-93.

90. Budweiser S, Baur T, Jorres RA, Kollert F, Pfeifer M, Heinemann F. Predictors of successful decannulation using a tracheostomy retainer in patients with prolonged weaning and persisting respiratory failure. Respiration. 2012;84(6):469-76.

91. Stelfox HT, Crimi C, Berra L, Noto A, Schmidt U, Bigatello LM, et al. Determinants of tracheostomy decannulation: an international survey. Crit Care. 2008;12(1):R26.

92. Tobin AE, Santamaria JD. An intensivist-led tracheostomy review team is associated with shorter decannulation time and length of stay: a prospective cohort study. Crit Care. 2008;12(2):R48.

93. Chan LY, Jones AY, Chung RC, Hung KN. Peak flow rate during induced cough: a predictor of successful decannulation of a tracheotomy tube in neurosurgical patients. Am J Crit Care. 2010 May;19(3): 278-84.

94. Rumbak MJ, Graves AE, Scott MP, Sporn GK, Walsh FW,Anderson 
WM, et al. Tracheostomy tube occlusion protocol predicts significant tracheal obstruction to air flow in patients requiring prolonged mechanical ventilation. Crit Care Med. 1997 Mar;25(3):413-7.

95. Bach JR, Saporito LR. Criteria for extubation and tracheostomy tube removal for patients with ventilatory failure: a different approach to weaning. Chest. 1996 Dec;110(6):1566-71.

96. Pasqua F, Nardi I, Provenzano A, Mari A; Lazio Regional Section, Italian Association of Hospital Pulmonologists (AIPO). Weaning from tracheostomy in subjects undergoing pulmonary rehabilitation. Multidiscip Respir Med. 2015 Nov;10:35.

97. Enrichi C, Battel I, Zanetti C, Koch I, Ventura L, Palmer K, et al. Clinical criteria for tracheostomy decannulation in subjects with acquired brain injury. Respir Care. 2017 Oct;62(10):1255-63.

98. Tabaee A, Lando T, Rickert S, Stewart MG, Kuhel WI. Practice patterns, safety, and rationale for tracheostomy tube changes: a survey of otolaryngology training programs. Laryngoscope. 2007 Apr;117(4): 573-6.

99. De Leyn P, Bedert L, Delcroix M, Depuydt P, Lauwers G, SokolovY, et al.Tracheotomy: clinical review and guidelines. Eur J Cardiothorac Surg. 2007 Sep;32(3):412-21.

100. Deutsch ES. Early tracheostomy tube change in children. Arch Otolaryngol Head Neck Surg. 1998 Nov;124(11):1237-8.

101. Mackenzie S, Murphy P, Bodenham A, Bell D, Bonner S, Branch F, et al. Standards for the care of adult patients with a temporary tracheostomy. London: The Intensive Care Society; 2008.

102. Mirza S, Cameron DS. The tracheostomy tube change: a review of techniques. Hosp Med. 2001 Mar;62(3):158-63.

103. Heffner JE, Hess D. Tracheostomy management in the chronically ventilated patient. Clin Chest Med. 2001 Mar;22(1):55-69.

104. Waldron J, Padgham ND, Hurley SE. Complications of emergency and elective tracheostomy: a retrospective study of 150 consecutive cases. Ann R Coll Surg Engl. 1990 Jul;72(4):218-20.

105. Yeo WX, Phua CQ, Lo S. Is routine chest X-ray after surgical and percutaneous tracheostomy necessary in adults: a systemic review of the current literature. Clin Otolaryngol. 2014 Apr;39(2):79-88.

106. Griffiths J, Barber VS, Morgan L, Young JD. Systematic review and meta-analysis of studies of the timing of tracheostomy in adult patients undergoing artificial ventilation. BMJ. 2005 May;330(7502): 1243.

107. Rodriguez H, Cuestas G, Zanetta A. Dysphonia in children due to congenital laryngeal web: case series. Arch Argent Pediatr. 2013 Jul-Aug;111(4):e82-5.

108. Saffle JR, Morris SE, Edelman L. Early tracheostomy does not improve outcome in burn patients. J Burn Care Rehabil. 2002 Nov-
Dec;23(6):431-8.

109. Terragni PP, Antonelli M, Fumagalli R, Faggiano C, Berardino M, Pallavicini FB, et al. Early vs late tracheotomy for prevention of pneumonia in mechanically ventilated adult ICU patients: a randomized controlled trial. JAMA. 2010 Apr;303(15):1483-9.

110. Bouderka MA, Fakhir B, Bouaggad A, Hmamouchi B, Hamoudi D, Harti A. Early tracheostomy versus prolonged endotracheal intubation in severe head injury. JTrauma. 2004 Aug;57(2):251-4.

111. Arabi YM, Alhashemi JA, Tamim HM, Esteban A, Haddad SH, Da$\operatorname{wood} \mathrm{A}$, et al. The impact of time to tracheostomy on mechanical ventilation duration, length of stay, and mortality in intensive care unit patients. J Crit Care. 2009 Sep;24(3):435-40.

112. Meng L, Wang C, Li J, Zhang J. Early vs late tracheostomy in critically ill patients: a systematic review and meta-analysis. Clin Respir J. 2016 Nov;10(6):684-92.

113. Wang F, Wu Y, Bo L, Lou J, Zhu J, Chen F, et al. The timing of tracheotomy in critically ill patients undergoing mechanical ventilation: a systematic review and meta-analysis of randomized controlled trials. Chest. $2011 \mathrm{Dec} ; 140(6): 1456-65$.

114. Young D, Harrison DA, Cuthbertson BH, Rowan K; TracMan Collaborators. Effect of early vs late tracheostomy placement on survival in patients receiving mechanical ventilation: the TracMan randomized trial. JAMA. 2013 May;309(20):2121-9.

115. Cipriano A, Mao ML, Hon HH, Vazquez D, Stawicki SP, Sharpe RP, et al. An overview of complications associated with open and percutaneous tracheostomy procedures. Int J Crit Illn Inj Sci. 2015 JulSep;5(3):179-88.

116. Klein M,Weksler N, Kaplan DM, Weksler D, Chorny I, Gurman GM. Emergency percutaneous tracheostomy is feasable in experienced hands. Eur J Emerg Med. 2004 Apr;11(2):108-12.

117. Delaney A, Bagshaw SM, Nalos M. Percutaneous dilatational tracheostomy versus surgical tracheostomy in critically ill patients: a systematic review and meta-analysis. Crit Care. 2006 Apr;10(2): R55.

118. Freeman BD, Isabella K, Lin N, Buchman TG. A meta-analysis of prospective trials comparing percutaneous and surgical tracheostomy in critically ill patients. Chest. 2000 Nov;118(5):1412-8.

119. SilvesterW, Goldsmith D, Uchino S, Bellomo R, Knight S, Seevanayagam S, et al. Percutaneous versus surgical tracheostomy: a randomized controlled study with long-term follow-up. Crit Care Med. 2006 Aug;34(8):2145-52.

120. Bacchetta MD, Girardi LN, Southard EJ, Mack CA, Ko W,Tortolani $\mathrm{AJ}$, et al. Comparison of open versus bedside percutaneous dilatational tracheostomy in the cardiothoracic surgical patient: outcomes and financial analysis. Ann Thorac Surg. 2005 Jun;79(6):1879-85. 